\title{
Influence of sintering atmosphere on the performance of porous silicon carbide ceramics
}

\author{
Hongsheng ${ }^{1, a^{*}}$, Kaihong Zhang ${ }^{1, b}$, Ziqiang $\mathrm{Li}^{1, \mathrm{c}}$, and Xiaoxue $\mathrm{Liu}^{1, \mathrm{~d}}$ \\ ${ }^{1}$ Institute of Nuclear and New Energy Technology, Collaborative Innovation Center of Advanced \\ Nuclear Energy Technology, Tsinghua University, Beijing 100084, China. \\ âhshzhao@tsinghua.edu.cn, bzkh@tsinghua.edu.cn, ${ }^{\mathrm{c} l i z i q i a n g @ t s i n g h u a . e d u . c n,{ }^{d} l i u x x 1 @ t s i n g h u a}$ \\ .edu.cn
}

Keywords: porous SiC ceramics, coat-mix, sintering atmosphere, performance

\begin{abstract}
The core-shell structure precursor powder was fabricated by coat-mix process in different fabrication conditions with various aging $\mathrm{pH}$ value. The porous silicon carbide ceramics were prepared through molding, carbonization, and sintering in argon atmosphere and vacuum, respectively. Morphology, physical phase, weight loss rate, density, porosity, bending strength and thermal shock resistance of porous silicon carbide ceramic samples were analyzed and the results show that the aging $\mathrm{pH}$ values of ceramic samples sintered in both of atmospheres have the consistent influence on the performance of the samples. The ceramic samples sintered in vacuum have a better bending strength and porosity, while ceramic samples sintered in Ar atmosphere have a better purity and toughness. When the $\mathrm{pH}$ value of aging process ranges from 3 to 5 , the porous $\mathrm{SiC}$ ceramic samples sintered in Ar atmosphere have a stable thermal expansion coefficient.
\end{abstract}

\section{Introduction}

Porous ceramic materials have many excellent properties, and are widely used in many fields ${ }^{[1-4]}$. The porous nature and stability at high temperature behave great advantage in the field of fireproofing materials, catalyst carriers, fluid filtration, high temperature membrane reactors, fluidized bed separators and electrolyte separators, etc. But porous ceramic materials need further improve, such as thermo mechanical properties, porosity and strength, materials aperture control and costs etc. Compared with conventional porous materials, porous silicon carbide ceramic materials possess high temperature strength, high thermal conductivity, corrosion resistance, oxidation resistance and thermal shock resistance, helping them maintain good stability to the hard conditions, and show their promising future as high-temperature ceramic filter materials ${ }^{[5-7]}$. There are many different ways to produce porous silicon carbide ceramics, which can be prepared to adapt different working environment ${ }^{[8-12]}$. The coat-mix process can make each silicon particle evenly coated by phenolic resin, which enhance the uniformity and eliminate internal stress. Mixing of binder and aggregate to the greatest degree is the key to fabricated porous SiC ceramic products with low molding pressure, high strength and high structural uniformity ${ }^{[10,13]}$. Porous silicon carbide ceramics synthesized through coat-mix process by adding a small amount of $\mathrm{Al}_{2} \mathrm{O}_{3}-\mathrm{SiO}_{2}-\mathrm{Y}_{2} \mathrm{O}_{3}$ additive have high porosity and both the thermal shock resistance and the thermal conductivity were enhanced ${ }^{[14]}$. The addition of $\mathrm{SiC}$ whisker enhances the bending strength of $\mathrm{SiC}$ matrix obviously and high temperature properties can maintain at a good level ${ }^{[15,16]}$ and the phenolic resin curing reaction is very sensitive to aging $\mathrm{pH}$ values and sintering atmosphere ${ }^{[17]}$. When the $\mathrm{pH}$ value rangesfrom 3 to 5 or higher than 7 , the phenolic resin shows a lower crosslink degree and char yield, while the ceramics show a higher porosity and a lower thermal expansion coefficient; and the flexural strength decreases as the aging environmental $\mathrm{pH}$ value increases.

In this paper, core-shell structure precursor powder was fabricated by coat-mix process in different fabrication conditions with various aging $\mathrm{pH}$ value. The porous silicon carbide ceramics were prepared through molding, carbonization, and sintering in argon atmosphere and vacuum, respectively. Morphology, physical phase, weight loss rate, density, porosity, bending strength and thermal shock resistance of porous silicon carbide ceramic samples were analyzed. 


\section{Experimental}

Materials. Porous SiC ceramics was prepared from industrial-grade silicon powder and barium phenolic resin through coat-mix process. Chemically pure $\mathrm{Y}_{2} \mathrm{O}_{3}$, analytically pure $\mathrm{SiO}_{2}$ chemically pure neutral $\mathrm{Al}_{2} \mathrm{O}_{3}$ as additives. Besides, $\mathrm{HCl}$ (mass fraction is $38 \%$ ) and $\mathrm{NaOH}$ (chemically pure solution) were used to adjust the $\mathrm{pH}$ values.

Fabrication of the porous silicon carbide ceramics. The core-shell structure precursor powder was prepared by coat-mix process ${ }^{[14]}$. Using $1 \mathrm{~mol} / \mathrm{L} \mathrm{HCl}$ or $\mathrm{NaOH}$ solution immediately to control aging $\mathrm{pH}$ value. After the turbid liquid being aged, settled, filtered and evaporated, the precursor powder was obtained. Adding a small amount of $\mathrm{Al}_{2} \mathrm{O}_{3}, \mathrm{SiO}_{2}$ and $\mathrm{Y}_{2} \mathrm{O}_{3}$ composite to the precursor powder as sintering additives and the porous $\mathrm{SiC}$ ceramic samples were fabricated Through molding, carbonization, and sintering process.

Characterization of the porous silicon carbide ceramics. The microscopic structure of block or powder samples were observed by Japan S-3000N type electron microscope. Weight loss was measured by synchronous thermal analyzer (STA449F). Thermal expansion coefficient was measured by thermal dilatometer (DIL-402CD). Porosity and pore size was tested by automated mercury analyzer (Autopore IV 9510). Physical phase composition was measured by X-ray diffraction (Bruker $\mathrm{P} 4)\left(\mathrm{Cu} \mathrm{K} \alpha, \lambda=1.5418 \mathrm{~A}\right.$, scanning range is $2 \theta=10^{\circ} \sim 80^{\circ}$, scan rate is $\left.2^{\circ} / \mathrm{min}\right)$. Three-point bending strength was measured by Zwick005 type universal material testing machine. The sample size is $3 \mathrm{~mm} \times 4 \mathrm{~mm} \times 40 \mathrm{~mm}$, with span of $30 \mathrm{~mm}$, and loading rate of $0.5 \mathrm{~mm} / \mathrm{min}$. The bending strength of porous silicon carbide ceramics can be calculated with formula (1).

$$
\sigma_{b b}=\frac{3 P_{b} L}{2 b h^{2}}
$$

Where, The $\sigma_{\mathrm{bb}}$ is sample bending strength (MPa), $P_{\mathrm{b}}$ is sample critical load $(\mathrm{N}), \mathrm{L}$ is pan $(\mathrm{mm}), b$ is sample width (mm), $h$ is sample thickness $(\mathrm{mm})$.

The ceramic samples were heated up to $800{ }^{\circ} \mathrm{C}$ and preserved for $30 \mathrm{~s}$, and then removed from the furnace and cooled down to room temperature. The heating and cooling process were repeated for 30 times. The thermal shock resistance of ceramic samples is characterized by bending strength loss rate after thermal shock test as follows:

$$
\eta=\frac{\sigma_{0}-\sigma_{1}}{\sigma_{0}} \times 100 \%
$$

Where, $\sigma_{0}$ is bending strength before thermal shock test; $\sigma_{1}$ is bending strength after thermal shock test.

\section{Results and discussion}

Phase analysis of porous silicon carbide ceramics. Pure $\beta$-SiC crystal is colorless and the porous silicon carbide ceramic samples present light yellow green because of impurity. The more impurity of porous silicon carbide ceramic samples contain, the deeper color they present. The appearance of the samples after sintered in argon atmosphere is light yellow green, while the samples after sintered in vacuum is black. Therefore, porous silicon carbide samples sintered in vacuum contain more impurity. Fig. 1 (a) and (b) show the typical XRD diffraction patterns $\left(2 \theta=10^{\circ} \sim 80^{\circ}\right)$ of porous silicon carbide ceramics sintered in argon and vacuum, respectively. The $\mathrm{pH}$ value in aging process of these two kinds of porous silicon carbide ceramic samples is 4 .

Fig. 1 shows that porous silicon carbide ceramics sintered in argon atmosphere only contain $\beta$-SiC phase. Diffraction peaks appear at $2 \theta$ of $36^{\circ}, 41^{\circ}, 60^{\circ}, 72^{\circ}$ and $76^{\circ}$ correspond to (111), (200), (220), (311) and (222) plane, respectively. No other peaks present in the XRD pattern, indicating the major phase of porous silicon carbide ceramic sintered in argon atmosphere of 0.4 atmosphere is pure $\beta$-SiC, and no free silicon, carbon or other phases appear as impurities. While samples sintered in vacuum also contain amount of $\mathrm{Si}$. Because the $\mathrm{SiC}$ and $\mathrm{Si}$ have a eutectic point, vacuum will constantly 
siphoned off the silicon of molten component, making the rest of the Si tend to form eutectic content with silicon carbide and influence the reaction of Si and C, and ultimately affect the purity of SiC.

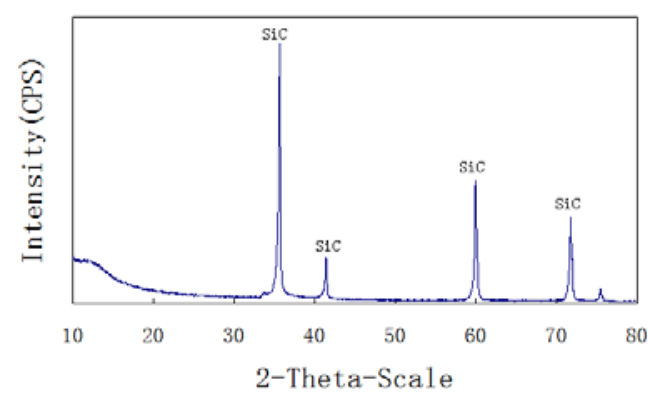

(a)

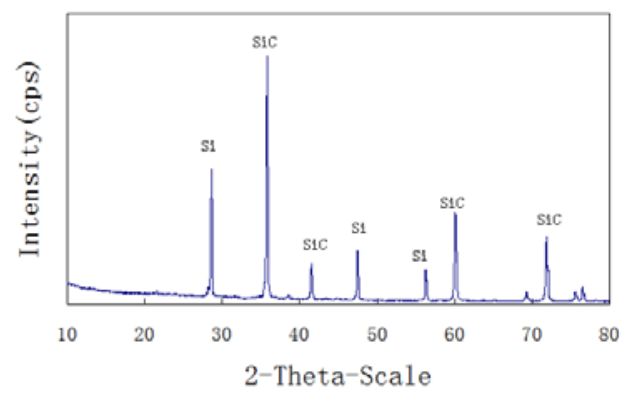

(b)

Fig. 1 XRD patterns of porous SiC ceramics sintered in (a) argon and (b) vacuum

Weight loss rate of ceramic samples during sintering process. Fig. 2 shows the weight loss rates varying curves of porous silicon carbide ceramic samples sintered in two kinds of atmospheres. The $\mathrm{pH}$ values of aging process range from 2 to 10. It can be seen that the trend of weight loss rates varying with aging $\mathrm{pH}$ values sintered in two kinds of atmospheres are almost the same. Compared to the other, sample weight loss rates sintered in vacuum are more sensitive to aging $\mathrm{pH}$ values, and the changes are more significant. The weight loss rate is lowest at $\mathrm{pH}$ value is 4 and 8 , while the weight loss rate is highest at $\mathrm{pH}$ value of 7 .

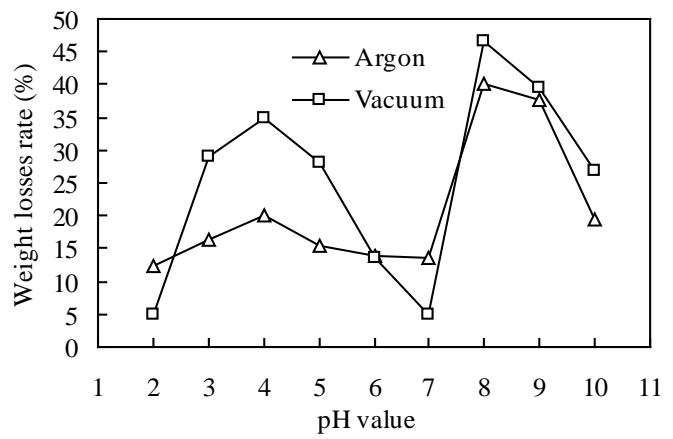

Fig. 2 Weight loss rates of porous SiC ceramics sintered in two atmospheres

The density and porosity of ceramic samples. The densities of porous silicon carbide ceramic samples sintered in the argon atmosphere and vacuum varying with $\mathrm{pH}$ values of aging process are shown as Fig. 3(a). It can be seen that the trend of densities of ceramic samples sintered in two kinds of atmospheres varying with aging $\mathrm{pH}$ values are almost the same. With the same $\mathrm{pH}$ value of aging process, ceramic samples sintered in different atmospheres have close density. Porosities of porous silicon carbide ceramic samples sintered in the argon atmosphere and vacuum varying with $\mathrm{pH}$ values of aging process are shown in Fig. 3(b). It shows that porosity of the silicon carbide sintered in vacuum is higher than that in argon atmosphere, while it has almost the same change trend. It indicates that the influence of $\mathrm{pH}$ values of aging process on the porosity of ceramic samples prepared in two kinds of sintering atmospheres is basically the same. The higher porosity sintered in vacuum is due to liquid Si volatilizing more easily in the absence of pressure state, leaving interspaces behind in ceramics. The difference is not obvious on the aperture size.

Morphologies of samples. Fig. 4 (a) and (b) are morphologies of porous silicon carbide ceramic samples sintered in the argon atmosphere and vacuum captured by scanning electron microscopy (SEM). It can be seen that, samples sintered in vacuum have thin pore wall, while samples sintered in argon atmosphere have the pore wall thick and smooth. This is because silicon is not easy to volatile in argon atmosphere, it is forced to overflow from channels of samples and react more fully with carbon skeleton on the surface under internal thermal stress, forming more massive silicon carbide. 


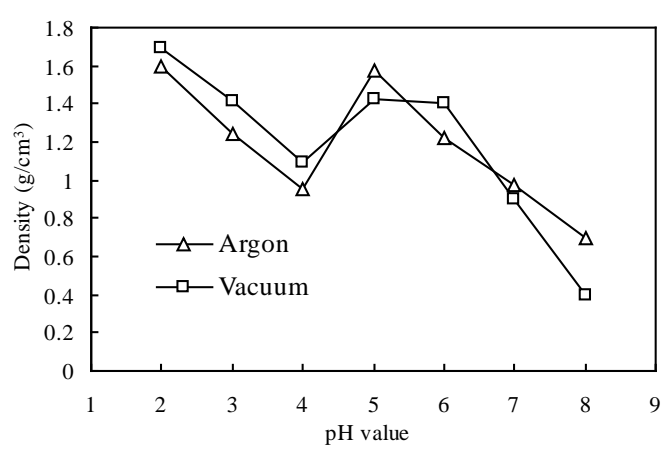

(a)

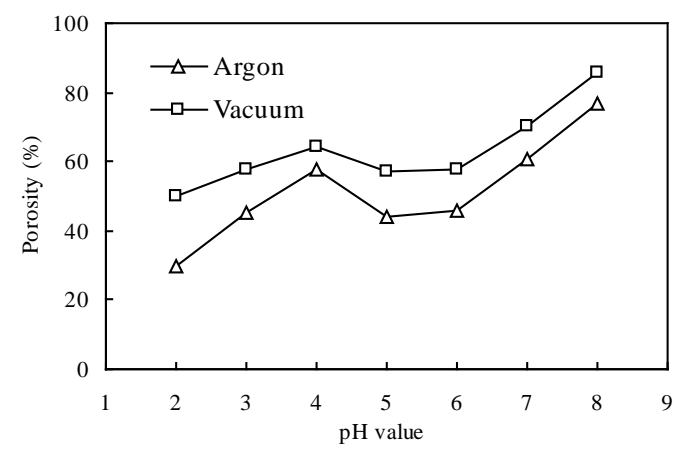

(b)

Fig. 3 (a) Density and (b) porosity of porous $\mathrm{SiC}$ ceramics varying with aging $\mathrm{pH}$ values in two atmospheres

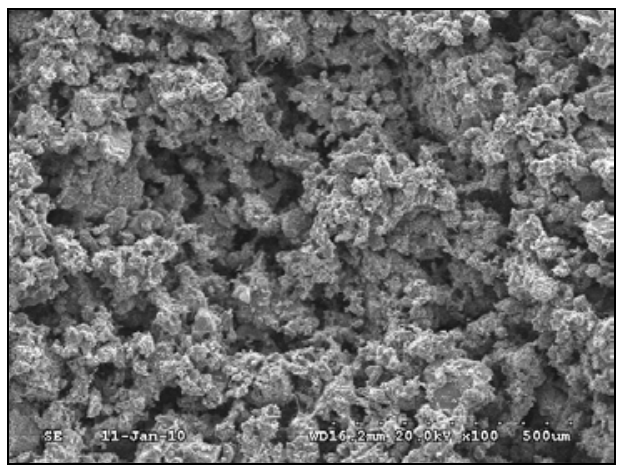

(a)

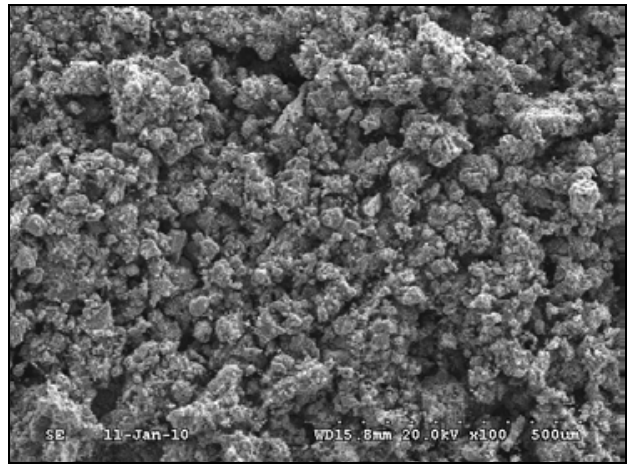

(b)

Fig. 4 SEM morphologies of porous SiC ceramics sintered in (a) argon atmosphere and (b) vacuum

Thermal expansion coefficients. The thermal expansion coefficients (TEC) of ceramic samples sintered in two kinds of sintering atmospheres with different $\mathrm{pH}$ values of aging process are shown in Fig. 5, in which shows that the thermal expansion coefficient of ceramic samples sintered in two kinds of atmospheres varying with aging $\mathrm{pH}$ values are basically consistent. By contrast, samples sintered in argon atmosphere with aging $\mathrm{pH}$ values between $3 \sim 5$ have stable thermal expansion coefficient.

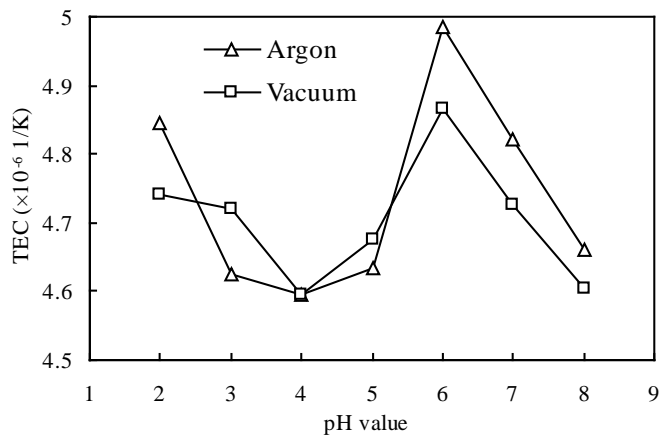

Fig. 5 Thermal expansion coefficients of porous SiC ceramics sintered in two atmospheres varying with aging $\mathrm{pH}$ values

Bending strength and thermal shock resistance. Fig. 6 (a) and (b) show that the bending strength of porous silicon carbide ceramic samples sintered in the argon atmosphere and vacuum, and the $\mathrm{pH}$ value of aging process is 4 . Fig. 6 shows that samples sintered in vacuum have higher bending strength, and the curve is very straight, which indicates that the samples are very brittle. Although samples sintered in argon atmosphere have lower strength, the curve rises slowly with many twists and turns, which indicating good toughness of the samples. 


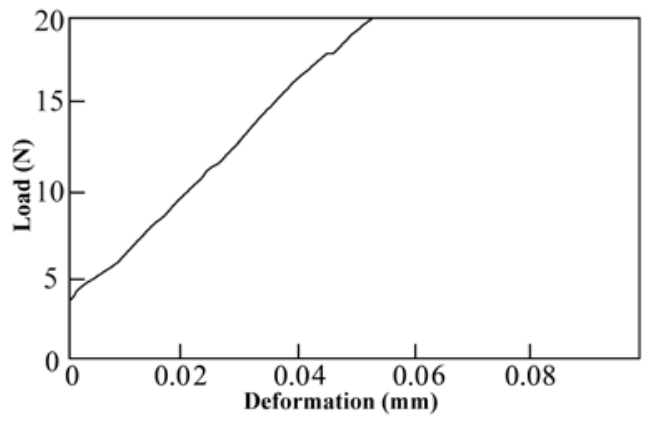

(a)

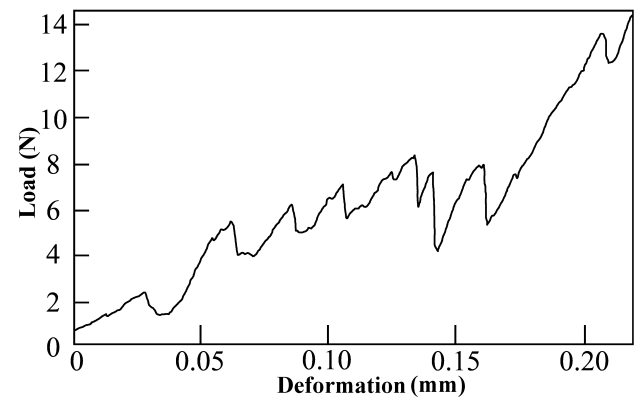

(b)

Fig. 6 Bending strength of porous SiC ceramics sintered in (a) argon atmosphere and (b) vacuum

Thermal shock resistance. Bending strength loss rate curves of samples sintered in two kinds of atmospheres varying with aging $\mathrm{pH}$ values are shown in Fig. 7, in which shows that samples sintered in vacuum have worse thermal shock performance. Although the thermal expansions in two kinds of sintering atmospheres are similar, bending strength tests shows obviously that samples sintered in vacuum are more brittle than that in argon atmosphere, influencing the thermal shock performance.

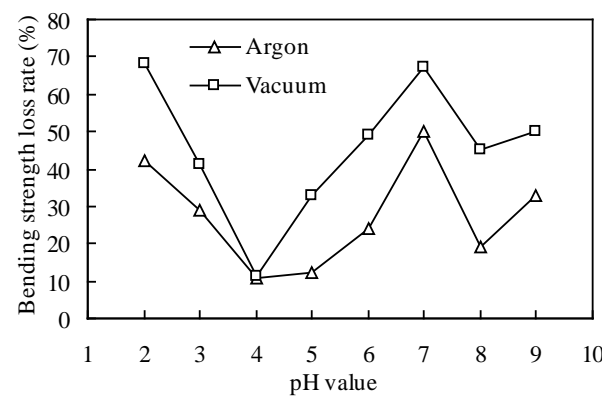

Fig. 7 Bending strength loss rate curves of porous SiC ceramics sintered in two atmospheres varying with aging $\mathrm{pH}$ values

\section{Conclusions}

The core-shell structure precursor powder was prepared by coat-mix process with various $\mathrm{pH}$ values in aging process, and the porous silicon carbide ceramics were fabricated through molding, carbonization, and sintering under $0.4 \mathrm{~atm}$ argon atmosphere and vacuum, respectively. Results show that the influence of aging $\mathrm{pH}$ value on the performance of the ceramic samples sintered in both of atmospheres is basically consistent. Ceramic samples sintered in vacuum have higher bending strength and porosity, while ceramic samples sintered under an argon atmosphere are proved to have high purity, good toughness, and the thermal expansion coefficient is more stable in the range of aging $\mathrm{pH}$ value $3-5$. Porous silicon carbide ceramics sintered in vacuum contain a small amount of silicon, and generate silicon carbide-silicon eutectic resultant at high temperature of $1400{ }^{\circ} \mathrm{C}$, which would greatly reduce the tolerance of silicon carbide ceramics to high temperature. However, this ceramics sintered in vacuum have high bending strength and high porosity at not too high environmental temperatures, and have a potential application prospects in many fields.

\section{Acknowledgement}

This work was financially supported by the National Natural Science Foundation of China (50802052).

\section{References}

[1] A.M. Alvin, E.T. Lippert, E.J. Lane. Assessment of porous ceramic materials for hot gas filtration applications. [J]. Am. Ceram. Soc. Bull., 1991, 70: 1491-1498. 
[2] J.W. Brockmeyer, L.S. Aubrey, J.E. Dore. Ceramic foam filter. [P]. U.S. Patent 4,975,191. (1990).

[3] E. Passalacqua, S. Freni, F. Barone. Alkali resistance of tape-cast SiC porous ceramic membranes. [J]. Mater. Lett., 1998, 34: 257-262.

[4] S. Kitaoka, Y. Matsushima, C. Chen, H. Awaji. Thermal cyclic fatigue behavior of porous ceramics for gas cleaning. [J]. J Am. Ceram. Soc., 2004, 87: 906-913.

[5] J.H. She, J.F. Yang, N. Kondo, T. Ohji, S. Kanzaki, Z.Y. Deng. High strength porous silicon carbide ceramics by an oxidation-bonding technique. [J]. J Am. Ceram. Soc., 2002, 85: 2852-2854.

[6] J.M. Qian, J.P. Wang, G.J. Qiao, Z.H. Jin. Preparation of biomorphic SiC ceramic by carbothermal reduction of oak wood charcoal. [J]. Mater. Sci. Eng. A, 2004, 371, 229-235.

[7] B.H. Yoon, E.J. Lee, H.E. Kim, Y.H. Koh. Highly aligned porous silicon carbide ceramics by freezing polycarbosilane/camphene solution. [J]. J Am. Ceram. Soc., 2007, 90: 1753-1759.

[8] W.W. Chen, Y. Miyamoto. Fabrication of porous silicon carbide ceramics with high porosity and high strength. [J]. J Eur. Ceram. Soc., 2014, 34: 837-840.

[9] S.Q. Ding, Y.P. Zeng, D.L. Jiang. In-situ reaction bonding of porous SiC ceramics. [J]. Mater. Charact., 2008, 59: 140-143.

[10] D. Simwonis, H. Thülen, F.J. Dias, A. Naoumidis, D. Stöver. Properties of Ni/YSZ porous cermets for SOFC anode substrates prepared by tape casting and coat-mix ${ }^{\circledR}$ process [J]. J Mater. Proc. Technol., 1999, 92-93: 107-111.

[11] A. Morancais1, F. Louvet, D.S. Smith, J.P. Bonnet. High porosity SiC ceramics prepared via a process involving an SHS stage. [J]. J Eur. Ceram. Soc., 2003, 23: 1949-1956.

[12] S.M. Zhu, S.Q. Ding, H.A. Xi, R.D. Wang. Low-temperature fabrication of porous SiC ceramics by preceramic polymer reaction bonding. [J]. Mater. Lett., 2005, 59: 595-597.

[13] L.M. Shi, H.S. Zhao, Y.H. Yan, C.H. Tang. Fabrication of high purity porous SiC ceramics using coat mix process. [J]. Mater. Sci. Eng. A, 2007, 460-461: 645-647.

[14] L.M. Shi, H.S. Zhao, Y.H. Yan, Z.Q. Li, C.H. Tang. High specific surface area porous SiC ceramics coated with reticulated amorphous SiC nanowires. [J]. Physica E, 2008, 40(7): 2540-2544.

[15] X.X. Liu, H.S. Zhao, H. Yang, K.H. Zhang, Z.Q. Li. Effect of SiC whiskers on the properties of porous silicon carbide ceramic. [J]. Mater. Res. Innovations, 2014, 18(suppl2): 157-161.

[16]H. Yang, H.S. Zhao, X.X. Liu, Z.Q. Li, K.H. Zhang, C.H. Tang. Microstructure evolution process of porous silicon carbide ceramics prepared through coat-mix method. [J]. Ceram. Int., 2012, 38(3): 2213-2218.

[17]H.S. Zhao, Z.G. Liu, Y. Yang, K. H. Zhang, ZQ. Li. Preparation and properties of porous silicon carbide ceramics through coat-mix and composite additives process. [J]. Trans. Nonferrous Met. Soc. China, 2011, 21(6): 1329-1334. 